\title{
EXAMPLE OF A PROTOTYPE APPLICATION FOR THE INTEGRATION OF MODERN ICT IN THE BUSINESS OF INDUSTRIAL PRODUCTION-BUSINESS SYSTEMS
}

\author{
Darko Stefanovic \\ Faculty of Technical Sciences, University of Novi Sad, darko.stefanovic@uns.ac.rs.
}

\begin{abstract}
Keywords: Business IS, ERP systems, ERP system success - effectiveness, production
\end{abstract} planning, work process preparation

\begin{abstract}
:
This study researches the frameworks or models of measuring success or effectiveness of the ERP systems. Also, this study develops a prototype software solution for production planning and work process preparation for a more detailed understanding of existing models and to develop a proposed success - an efficiency model in the context of ERP systems.
\end{abstract}

\section{INTRODUCTION}

In the modern economy, companies, as business entities, are autonomous in the planning of development and business. Furthermore, they are autonomously determing development goals and business policy, taking into account the wider restrictions on the environment and general business conditions. Industrial system - enterprise refers to the existence of a set of elements - objects of labor, means of labor and participants in the work processes, interconnected work processes that enable the conversion of input materials, based on the information given and with the investment of the required energy - electrical, thermal, pressurized air and bioenergy participants in the processes of working in products of sufficient quality to meet the needs of consumers. [1]

At its core, production planning is the basis of every production process. Its purpose is to minimize production time and costs, effectively organize resource usage and optimize workplace efficiency. Production planning encompasses a multitude of production elements, ranging from the day-to-day activities of staff to the ability to achieve the correct delivery time to clients. With effective production planning, any form of production has the potential to reach its full potential. Numerous definitions of the term planning are found in the literature. One of the commonly used is: "Planning is a managerial function that selects an effective course of action to obtain, allocate, use and replace an organization's resources." The term "dialing" here refers to the choice of several alternative solutions. [2].

The production planning subsystem has the task of aligning the requirements of the environment and the capabilities of the system with the production of production orders to enable the realization of all that is planned and prepared for production purposes. The Production Planning subsystem contains the Process Preparation process, which, in addition to the Production Planning subsystem, is the subject of research in paper. 
Darko Stefanovic - Example of a Prototype Application for the Integration of Modern ICT in the Business of Industrial Production-Business systems.

\subsection{CAPM - Computer Aided Production Management}

Throughout the history and development of solutions that would enable the automation of the business process, since 1956, it has moved quite a distance from manufacturing itself, and thus from production management. Development was based on CAM2, CAD3 and CAE4 systems until the 1970s. Since then, up until the 2000s, the trend continued in the path of development of production planning systems rather than production management systems. This period of time marks the development of MRP5 MRPII6 and ERP7 systems, which are later described in depth. Finally, it comes down to CAPM, which in the present day, in this region, could be observed from a wider theoretical aspect as well as practical, ie. observation of specific cases introducing the system into business and adapting it.

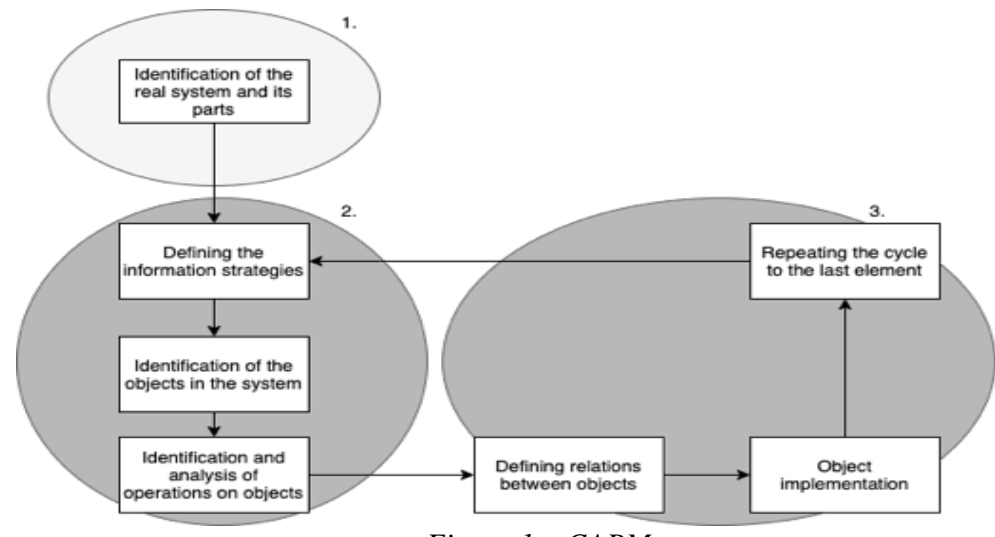

Figure $1-C A P M$

New software systems with an emphasis on optimizing production processes during the 1970s. These systems synchronized requests for material with requests for production, and became known as production resource planning systems (Manufacturing Resource Planning - MRP II). MRP II systems provided closed loop systems, considering capacity when developing production schedules [3]. In the late 1980s, innovations in ICT led to the development of a range of software applications aimed at integrating information flow across the organization. ERP systems have thus attracted the attention of some of the world's largest companies [4]. Enterprise Resource Planning - ERP systems, have been promoted by the American Production and Inventory Control Society - APICS since 1980 and can be considered the next generation of MRP II systems. They combine the functionality of the MRP II system with other areas of application such as: quality, maintenance, marketing, accounting, etc. However, ERP systems also contain certain modules that were not originally used in MRP II systems such as Computer Aided Design - CAD, Distribution Resource Planning - DRP, Tool Management Systems - TMS, and Product Data Management - PDM [6]. The ERP system is the first approach that integrates business management and IT concepts integrally [7]. The ERP system is used not only in manufacturing organizations, but in every organization that wants to improve competitiveness by using all of its resources, including information, most effectively. [8].

ERP systems are a complete enterprise-level business solution, deploying a unique set of tools to plan required resources across the organization, enabling real-time integration of all sectors of the organization and connecting suppliers and consumers into a single supply chain. Acceptance of ERP systems within large manufacturing organizations requires the integration of work practices (habits) and information systems [9]. 
Darko Stefanovic - Example of a Prototype Application for the Integration of Modern ICT in the Business of Industrial Production-Business systems.

\section{METHODOLOGY}

In accordance with the stated goals of this paper it is possible to define the research question of the subject research:

RQ1: Is it possible and necessary to apply modern methods and techniques in the field of designing databases and applications that work for the quality and efficient realization of the prototype of the information subsystem preparing the work process within the production planning module?

The development of a prototype of a software solution for production planning and process preparation was started by designing a conceptual database schema. There are two approaches to designing a conceptual database schema [5]:

- a direct process, when all the end-user requirements for all database applications are combined into one request and a single schema is created, and then the external schemas are designed according to the user requirements, based on the conceptual schema and verifying the needs of future applications;

- gradual integration, the reverse process of first designing external schemas and then, by integrating them, a conceptual schema.

In the course of this project, a direct design procedure was used in the conceptual database schema design, without the creation of external schemas because it is a general approach to the problem. The conceptual schema integrates all the information for the information needs of the system for automated production planning and preparation of the work process. The Entity Relationship Diagram (ER) is created at the level of detail of the features for the production planning and workflow preparation modules. The database implementation schema in the form of Relational Data Model (RDM) is the result of automated translation of the created ER model.

After the implementation of the implementation schema was generated and the database objects were created, the application design was started. A prototype of a software solution for production planning and process preparation has been developed, consisting of several modules of the screen form type intended for user interaction that are interconnected by the menu module.

\section{RESULTS}

This chapter introduces parts of a prototype application for production planning and process preparation. The developed prototype of the application for production planning and workflow preparation consists of several modules of screen form type grouped into categories: administration, operational plan, production order, resources, workflow, component and inventory management, which are interconnected by the module menu. The menu module consists of basic submenus with its own structures and is used to navigate within the prototype of the developed application. The menu module consists of basic submenus with their own structures and is used to navigate within the prototype of the application. The accessibility of certain parts of the prototype application is defined based on the access rights of user accounts.

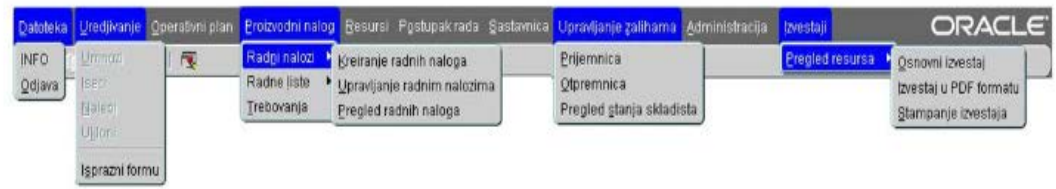

Figure 2 - Application menu structure for production planning and process preparation

The administrative part of the developed prototype of the software solution includes mechanisms for keeping records /catalogs of user accounts, types of warehouses and warehouses, business partners and 
Darko Stefanovic - Example of a Prototype Application for the Integration of Modern ICT in the Business of Industrial Production-Business systems.

organizational units. The management of user accounts includes CRUD (Create, Read, Update and Delete) operations for users. The management of warehouse types and warehouse records/registers is provided through on-screen forms that allow users to enter, view, modify and delete information about warehouse types and the warehouses themselves. The management of organizational units, involves the recording (creation), modification and deletion of organizational units and organizational structures. It is implemented through the on-screen form for administration, i.e. management of organizational units. The management of business partners within the prototype of a software solution involves keeping evidence catalog of associates (partner partners) and types of cooperation achieved. The screen form through which these activities are performed.

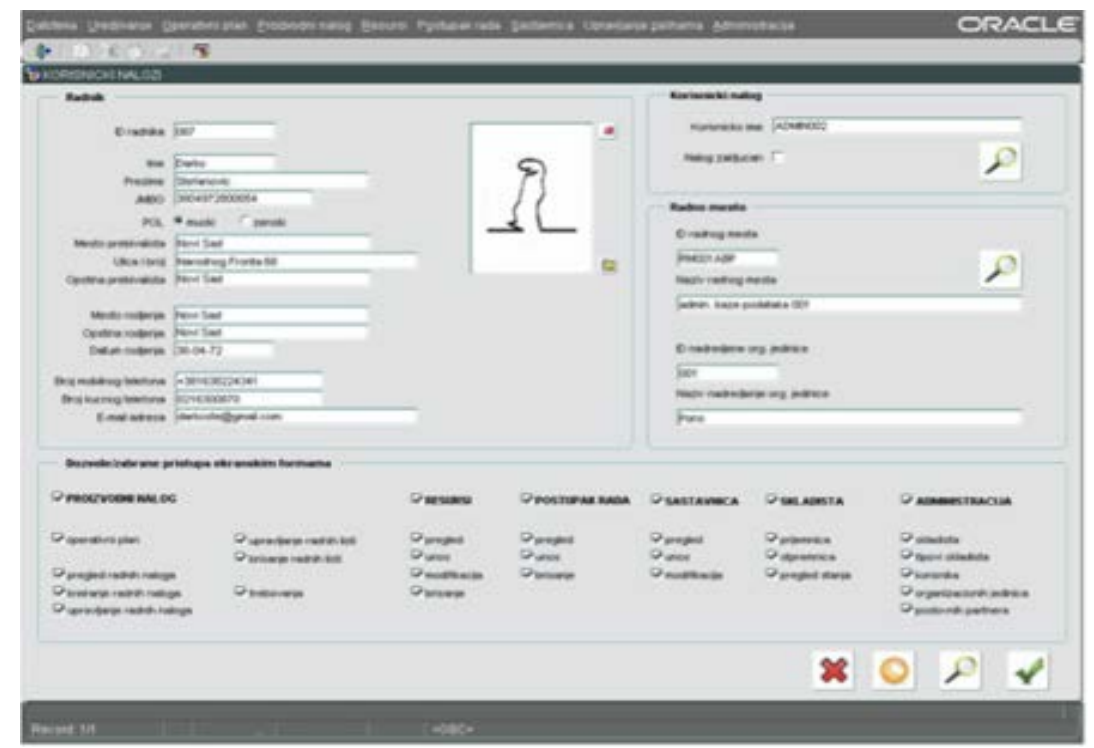

Figure 3 - The administrative part of the developed prototype

An operational plan is established for a specified period of time based on the availability of resources of work systems and environment, ie. capacities, materials, tools, energy resources, participants in the work process and cash as resources. Environmental character dynamics, disruptions in work processes, delivery delays, organizational and other influences condition the need to adjust operational plans. 
Darko Stefanovic - Example of a Prototype Application for the Integration of Modern ICT in the Business of Industrial Production-Business systems.

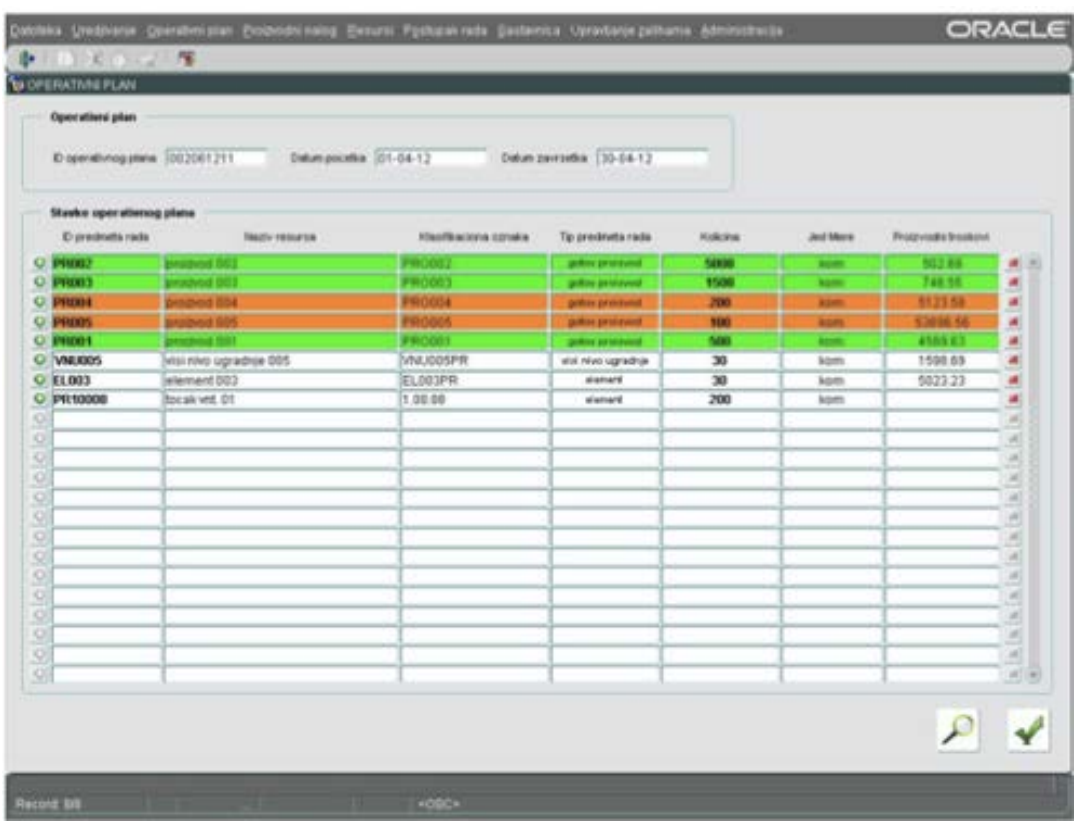

Figure 4 - On-screen form for working with operational plans

The aim of the process of designing production orders is to provide a basis for the participants in the work process to perform the process of changing the situation and to enable the flow control in the system. Input information are the elements of a production plan, and the executor is the structure over a set of jobs within which work process preparation tasks are performed as part of production planning procedures. The purpose of a work order is to provide a basis for the production or assembly of a part or a product and an analysis of the costs and expenses incurred in the work process. After completing the process of making or assembling a part or a product, the on-line work order creation form provides the process of unified creation of required work orders. In this application, parts for managing work orders and for reviewing work orders are also separately created. Similar to the procedures described above, support for worksheets, requisition, resources, and bill of materials was implemented.

\section{CONCLUSION}

The achieved result in this paper related to the development of the application prototype is a general, flexible and open prototype application of the computer-aided subsystem for production planning and preparation of work processes in industrial production and business systems. It is built using Oracle development tools to increase the efficiency and effectiveness of production within the production planning and workflow preparation functions for which an application prototype has been developed. Designing and building prototypes of an application are largely governed by the software tools used in the process. Oracle development tools used by the author automate most of the manual, often repetitive, error-prone work, and have significantly increased the productivity and precision of designing the prototype solution itself. 
Darko Stefanovic - Example of a Prototype Application for the Integration of Modern ICT in the Business of Industrial Production-Business systems.

Directions for further research regarding the developed prototype application for production planning and process preparation may include:

- improving the developed prototype of the application in terms of its capabilities and/or ease of use by users,

- extending the functionality of the developed application solution based on the elaborated conceptual database schema developed in a broader context than the observed functions of the application prototype and

- $\quad$ additional development of the application prototype to the level of the final solution suitable for implementation into a specific industrial production business system.

The author considers that the set goals have been satisfactorily fulfilled, with significant possibilities for improvement and improvement of the automated system for production planning and preparation of the work process obtained as a result of this paper.

\section{REFERENCES}

[1] Zelenovic, D. (2001). Technology of the Organization and Effective Management. Faculty of Technical Sciences, Novi Sad.

[2] Douma, S., Schreuder, H. (2002). Economic Approaches to Organizations (Third Edition). Prentice Hall.

[3] Wight, O., (1984). Manufacturing Resource Planning: MRP II. Oliver Wight Ltd. Publications, Williston, VT.

[4] O’Brien, J. (1999). Management Information Systems. McGraw-Hill Inc., London.

[5] Dewey, B. I., and DeBlois, P. B. (2006). Current IT issues survey report, 2006. EDUCAUSE Quarterly Magazine, 29(2), 12-30.

[6] Yusuf, Y., (1998). An empirical investigation of enterprise-wide integration of MRPII. International Journal of Operations and Productions Management 18 (1), pp. 66-86.

[7] K. Slooten, L. Yap, Implementing ERP information systems using SAP, in: Proceedings of the Americas Conference on Information Systems (ACIS), Milwaukee, WI, USA, August 13-15, 1999, pp. 226-228.

[8] Cruz-Cunha, M. M. and Varajao, J. (2011.). E-Business Issues, Challenges and Opportunities for SMEs: Driving Competitiveness, Business science reference, Hershey, New York.

[9] Mandal, P., Gunasekaran, A., (2002). Application of SAP R/3 in on-line inventory control. International Journal of Production Economics 72, pp. 47-55. 